\title{
Divergência genética entre linhagens de melão do grupo Inodorus ${ }^{1}$
}

\author{
Genetic divergence among lineages of melon of the group Inodorus
}

\author{
Glauber Henrique de Sousa Nunes², Dalila Regina Mota de Melo² ${ }^{*}$, Django Jesus Dantas², Fernando Antônio de \\ Souza Aragão ${ }^{3}$ e Elaíne Welk Lopes Pereira Nunes ${ }^{2}$
}

\begin{abstract}
Resumo - O presente trabalho teve como objetivo estimar a divergência genética entre linhagens Pele de Sapo e entre linhagens Honey Dew. Foram avaliadas dez linhagens de melão Pele de Sapo e dez linhagens de melão Honey Dew, em experimentos separados, conduzidos em blocos casualizados com três repetições. A divergência genética foi estimada pela distância de Mahalanobis. Foram utilizados os métodos de Tocher e UPGMA para o agrupamento das linhagens. Para as linhagens Pele de Sapo, constatou-se divergência genética com a formação de quatro e cinco grupos conforme os métodos de agrupamento de Tocher e UPGMA, respectivamente. Sugere-se cruzamento das linhagens PS-01, PS-05 e PS-7 entre si ou com as demais linhagens do grupo I. Para as linhagens Honey Dew, verificou-se a formação dos mesmos três grupos nos métodos de agrupamento de Tocher e UPGMA. O grupo II formado pelas linhagens OF-01 e OF-02; o grupo III pela linhagem OF-03 e o primeiro grupo pelas demais linhagens. Com relação às linhagens Honey Dew, recomenda-se os cruzamentos das linhagens OF-01 ou OF-02, com as demais linhagens avaliadas. A linhagem OF-03, com características semelhantes às linhagens OF-01 ou OF-02 pode ser cruzada com as linhagens do grupo I.
\end{abstract}

Palavras-chave - Cucumis melo. Heterose. Escolha de genitores. Distância de Mahalanobis.

\begin{abstract}
The objective of this work was to study the genetic divergence among lines of Pele de Sapo melon and among lines of Honey Dew melon. Ten lines of Pele de Sapo melon and ten lines of Honey Dew melon were evaluated, in separate experiments, both carried in a randomized block design with three replications. The divergence was estimated by the Mahalanobis distance. The methods of Tocher and UPGMA were used for the grouping of the lineages. For the lineages Pele de Sapo, genetic divergence was verified with the formation of four five groups according to the methods of grouping of Tocher and UPGMA, respectively. Must be made crosses among lines PS-01, PS-05 and PS-07 or between theses and other lines of group I. For the lineages of Honey Dew, the formation of the same three groups was verified in the methods of grouping of Tocher and UPGMA. The group II formed by lines OF-01 and OF-02; the group III by line OF-03 and first group by other lines. Considering Honey Dew lines, suggest crosses of lines OF-01 and OF-02 with other lines. The line OF-03 resembling to lines OF-01 and OF-02 must be crossed with the lines of group I.
\end{abstract}

Key words - Cucumis melo. Heterosis. Choice of parents. Mahalanobis distance.

\footnotetext{
* Autor para correspondência

${ }^{1}$ Recebido para publicação em 05/02/2010; aprovado em 10/03/2011

Pesquisa realizada pelos autores na Universidade Federal Rural do Semi-Árido - RN

${ }^{2}$ Departamento de Ciências Vegetais/UFERSA, Caixa Postal 137, Mossoró, RN, Brasil, 59.625-900, gauber@ufersa.edu.br, dalilaregina@hotmail.com, djdagr@hotmail.com, elainewelk@hotmail.com

${ }^{3}$ Pesquisador da Embrapa Agroindústria Tropical, Fortaleza-CE, Brasil, 60.511-110, aragão@cnpat.embrapa.br
} 


\section{Introdução}

O Rio Grande do Norte é o maior produtor e exportador de frutos de melão (Cucumis melo L.) do Brasil. A produção de melão está concentrada na região denominada de pólo agrícola Mossoró-Assu, na qual o meloeiro encontra condições muito favoráveis de luminosidade, temperatura e fotoperíodo para o seu desenvolvimento (FREITAS et al., 2007). Associado às boas condições climáticas está o uso de alta tecnologia por parte das empresas produtoras, permitindo que a cultura atinja produtividades acima de $25 \mathrm{t} \mathrm{ha}^{-1}$ (NUNES et al., 2004).

Dentre os híbridos existentes, aqueles pertencentes à variedade botânica Inodorus Naud. são os mais cultivados. O maior destaque é o tipo amarelo em razão da maior conservação pós-colheita, condições mais simples de manejo e transporte. Corresponde a mais de $60 \%$ do melão exportado, seguido dos tipos Honey Dew com 15,1\% e Pele de Sapo com 9,29\% das exportações, sendo este último preferido, principalmente, no mercado espanhol (SALES JÚNIOR et al., 2006).

O desenvolvimento de híbridos envolve a obtenção de linhagens com nível adequado de homozigose, avaliação das linhagens e seu cruzamento para obtenção de semente do híbrido $\mathrm{F}_{1}$. A obtenção das linhagens é facilitada porque em cucurbitáceas a depressão por endogamia é reduzida (CRAMER; WEHNER, 1999). Não obstante, a heterose tem sido explorada no meloeiro, sendo o emprego de híbridos uniformes uma das razões do sucesso da cultura. Híbridos simples de melão começaram a ser cultivados nos final dos anos 80 no Rio Grande do Norte. Atualmente as cultivares plantadas, em quase sua totalidade, são híbridos simples andromonóicos. Exceções são variedades de polinização aberta de melão do tipo Honey dew (GUSMINI; WEHNER, 2008).

Os melhoristas têm empregado processos preditivos para estudar a dissimilaridade genética entre linhagens para identificar aquelas que, quando cruzadas, possibilitem maior efeito heterótico. As técnicas multivariadas têm-se mostrado eficientes para fornecer informações sobre a divergência genética de um grupo de indivíduos ou populações, possibilitando a identificação de genitores potenciais em várias oportunidades. Existem muitos relatos sobre estudos de divergência genética em diversas hortaliças (GATTI et al., 2003; MALUF et al., 1983; MARTINELLO et al., 2002; MIRANDA et al., 1988;). No entanto, no caso específico do melão, há poucos trabalhos na literatura nacional a respeito desse tema. Dois grupos de linhagens de melão rendilhado, um formado pelas linhagens JAB-20, JAB-21 e 'Bônus 02', e o outro pelas linhagens JAB-22 e JAB-23, foram observados por Rizzo e Braz (2002). Braz et al. (2004) avaliando a divergência genética de vinte linhagens de melão rendilhado, obtiveram sete grupos de similaridade, sendo um formado por 14 genótipos e seis formados por um genótipo cada.

Diante do exposto, o presente trabalho teve como objetivos estimar a divergência genética entre linhagens Pele de Sapo e entre linhagens Honey Dew, a fim de indicar cruzamentos para geração de híbridos para a região Nordeste.

\section{Material e métodos}

Os experimentos foram conduzidos entre junho e setembro/2004 em Mossoró, município do Rio Grande do Norte, situado a $5^{\circ} 11^{\prime}$ de latitude Sul e $37^{\circ} 20^{\prime}$ longitude Oeste de Greenwich e $18 \mathrm{~m}$ de altitude. O clima, segundo a classificação de Koppen é 'BSWh' (muito seco, com estação de chuva no verão atrasando-se para o outono) (CARMO FILHO; OLIVEIRA, 1989).

No primeiro experimento foram avaliadas doze linhagens Pele de Sapo, sendo as linhagens PS-01; PS02; PS-03; PS-04; PS-05; PS-06; PS-07 e PS-08 obtidas do cruzamento entre os híbridos HPS-07 e Tendency. As linhagens PS-09; PS-10; PS-11 e PS-12 foram obtidas do híbrido Sancho. Todas as linhagens desse grupo têm polpa branca e expressão sexual andromonóica. No segundo experimento foram avaliadas doze linhagens do tipo Honey Dew. As linhagens OF-01; OF-02; OF-03; OF-04; OF-05, com polpa do fruto de cor salmão, foram obtidas do híbrido Honey Dew Red Flesh. As linhagens OF-06; OF-07; OF-08 e OF-09, com polpa do fruto esverdeada, foram obtidas do híbrido Saturno. Por fim, as linhagens OF-10, OF-11 e OF-12, com polpa salmão, foram obtidas do híbrido Orange Flesh. A expressão sexual de todas as linhagens é do tipo andromonóica.

As linhagens foram obtidas pelo método SSD (Single Seed Descendent) com modificações. A população $\mathrm{S}_{0}$ foi composta de 500 plantas, originadas da autofecundação de híbridos (Sancho, Honey Dew Red Flesh, Saturno e Orange Flesh) ou do cruzamento entre os híbridos simples PS $07 \mathrm{x}$ Tendency. As plantas foram identificadas e realizaram-se as autofecundações por oito gerações. Em cada geração, foram colhidos dois frutos por planta, misturaram-se as sementes de ambos e retirou-se uma semente para formar a próxima geração de autofecundação. Durante todo o processo as plantas com má formação de frutos e com alta susceptibilidade ao fungo Podosphaera xantii, agente causal do oídio, foram eliminadas. Posteriormente, as linhagens obtidas foram avaliadas, no primeiro momento, em ensaio em blocos aumentados e, em uma segunda etapa, em experimentos com repetições em dois locais, selecionando-se as linhagens avaliadas neste trabalho. 
Nos dois experimentos, a cultura foi irrigada por gotejamento, com fertirrigação, no espaçamento de $2,0 \mathrm{~m}$ entre linhas e $0,5 \mathrm{~m}$ entre gotejadores. O volume de água esteve em torno de $3.000 \mathrm{~m}^{3} \mathrm{ha}^{-1}$. Os fertilizantes foram aplicados de acordo com as recomendações baseadas na análise do solo. A adubação de fundação (em $\mathrm{kg} \mathrm{ha}^{-1}$ ) consistiu de $130 \mathrm{~N}, 270 \mathrm{~K}_{2} \mathrm{O}$ e 85 de $\mathrm{P}_{2} \mathrm{O}_{5}$. As fontes de minerais fornecidas via água de irrigação, em kg ha-1, foram: 450 de $\mathrm{KCl}, 120$ de Uréia, 450 de $\mathrm{CaNO}_{3}$ e 210 de $\mathrm{H}_{3} \mathrm{PO}_{4}$. As demais práticas culturais foram realizadas conforme a recomendação de manejo para a cultura no estado (NUNES et al., 2005).

Utilizou-se o delineamento de blocos completos casualizados com quatro repetições para linhagens Pele de Sapo, e três repetições, para linhagens Honey Dew. Cada parcela foi constituída por duas linhas medindo 5 metros de comprimento, contendo 10 plantas cada.

As características avaliadas para os grupos de melão Pele de Sapo e Honey Dew estão listadas na Tabela 4. A descrição de cada característica foi apresentada em detalhes por Torres Filho (2008). Para avaliação das características diâmetro longitudinal, diâmetro latitudinal, índice de formato, cavidade interna, espessura da polpa, firmeza da polpa, teor de sólidos solúveis e perda de peso, foi considerada uma amostra aleatória de 10 frutos por parcela.

Foram realizadas análises de variância univariada para todas as características avaliadas e posterior agrupamento de médias conforme Scott-Knott (BHERING et al., 2008). Posteriormente, realizou-se a análise de variância multivariada e aplicação do critério de Wilks a $5 \%$ de probabilidade. A partir da matriz com as médias de cada característica para cada linhagem e da matriz de variância-covariância residual, foram calculadas as distâncias generalizadas de Mahalanobis $\left(\mathrm{D}_{\mathrm{ij}}^{2}\right)$, conforme descrição de Cruz et al. (2004). Realizou-se o diagnóstico de multicolinearidade da matriz de correlação residual pelo método de Montgomery e Peck (1981). A análise de agrupamento foi realizada com a matriz de distâncias de Mahalanobis entre as linhagens, utilizando o método aglomerativo de Tocher e o método hierárquico UPGMA (agrupamento pareado não ponderado, baseado na média aritmética). Foi utilizado o critério de Singh, descrito por Cruz et al. (2004), para identificar a contribuição relativa de cada característica para a divergência genética. Todas as análises foram processadas no software GENES (CRUZ, 2008).

\section{Resultados e discussão}

Em experimentos de avaliação de genótipos em um programa de melhoramento genético é imprescindível ter elevada precisão para que as diferenças entre os materiais avaliados possam ser detectadas. O coeficiente de variação (CV) é a medida mais utilizada para se comparar a precisão experimental. No presente trabalho, as estimativas dos CV's de Pele de Sapo e Honey Dew variaram de 28,39 a 3,10 e 15,97 a 2,42, respectivamente, estando assim dentro da faixa observada para a cultura em outros trabalhos de avaliação de cultivares (GURGEL et al., 2005; NUNES et al., 2005). Os valores verificados podem ser classificados como médios conforme a classificação estabelecida por Lima et al. (2004) para o meloeiro.

As linhagens Pele de Sapo diferiram entre si para todas as características avaliadas (TAB. 1). As linhagens PS-10 e PS-11 destacaram-se com as maiores estimativas da média para as características produtividade, número total de frutos e número de fruto por planta. Com relação à produtividade, Dias et al. (1998) relatam que a produtividade de meloeiro no nordeste tem um intervalo de variação entre 17 e $30 \mathrm{t} \mathrm{ha}^{-1}$. No caso do melão Pele de Sapo, Nunes et al. (2005) verificaram produtividades entre 27 e 52,4 t ha ${ }^{-1}$, com média de 38,0 t ha ${ }^{1}$, no Rio Grande do Norte. Tomando-se com base as estimativas da literatura, mesmo com cautela, as linhagens PS-10 e PS-11 podem ser produtivas.

As linhagens PS-04; PS-05; PS-07 e PS-10 sobressaíram-se com frutos maiores. Em melão do tipo Pele de Sapo, frutos entre 3,0 e 4,0 kg são preferidos, em especial pelo mercado espanhol, bem como o mercado americano. Assim sendo, para essas linhagens, os frutos poderiam ser comercializados no mercado externo.

Todos os frutos apresentaram índice de formato superior a um. É notório que frutos alongados, com diâmetro longitudinal superior ao diâmetro transversal, e, portanto, índice de formato superior a 1,0, é inerente ao melão Pele de Sapo. Esse tipo de melão é aceito comercialmente com esse formato, embora, recentemente, algumas empresas holandesas estejam colocando no mercado melões menores e esféricos, semelhantes ao tipo Gália.

As linhagens PS-01 e PS-11 apresentaram as menores cavidades internas, enquanto a linhagem PS-06 apresentou a maior espessura da polpa. A experiência dos produtores tem mostrado que frutos de melão do tipo Pele de Sapo quando colhidos com firmeza de polpa na faixa de 26 a $28 \mathrm{~N}$ chegam às prateleiras européias com boa conservação pós-colheita. Com efeito, pode-se inferir, a partir das estimativas das médias de firmeza da polpa do presente trabalho, que apenas $50 \%$ das linhagens estariam adequadas para exportação (TAB. 1).

A linhagem PS-07 sobressaiu-se com maior firmeza da polpa e maior teor de sólidos solúveis. O teor de sólidos solúveis ( $\mathrm{SS}$ ), definido como a percentagem 
Tabela 1 - Médias de onze características avaliadas em doze linhas de melão Pele de Sapo. Mossoró-RN, 2004

\begin{tabular}{|c|c|c|c|c|c|c|c|c|c|c|c|}
\hline \multirow{3}{*}{ Linha } & \multicolumn{11}{|c|}{ Médias (características) } \\
\hline & PROD & \multirow{2}{*}{ NTF } & \multirow{2}{*}{ NFP } & \multirow{2}{*}{$\begin{array}{c}\mathrm{PMF} \\
\mathrm{kg}\end{array}$} & \multirow{2}{*}{$\begin{array}{l}\mathrm{DT} \\
\mathrm{cm}\end{array}$} & \multirow{2}{*}{$\begin{array}{l}\mathrm{DL} \\
\mathrm{cm}\end{array}$} & \multirow{2}{*}{ IF } & \multirow{2}{*}{$\frac{\mathrm{CI}}{\mathrm{cm}}$} & \multirow{2}{*}{$\begin{array}{l}\mathrm{EP} \\
\mathrm{cm}\end{array}$} & \multirow{2}{*}{$\frac{\mathrm{SS}}{\%}$} & \multirow{2}{*}{$\begin{array}{c}\mathrm{FP} \\
\mathrm{N}\end{array}$} \\
\hline & $\mathrm{t} \mathrm{ha}^{-1}$ & & & & & & & & & & \\
\hline PS-01 & $17,44 \mathrm{c}$ & $14254,3 b$ & $1,08 \mathrm{c}$ & $2,46 b$ & $15,9 b$ & $20,9 b$ & $1,3 b$ & $5,2 \mathrm{c}$ & $4,6 b$ & $8,8 \mathrm{~b}$ & $22,6 \mathrm{c}$ \\
\hline PS-02 & $24,49 b$ & $17784,3 b$ & $1,33 \mathrm{c}$ & $2,61 b$ & $16,4 b$ & $21,6 b$ & $1,3 b$ & $6,6 a$ & $4,0 \mathrm{c}$ & $9,1 b$ & $21,5 \mathrm{c}$ \\
\hline PS-03 & $14,18 \mathrm{c}$ & $10874,4 b$ & $0,06 \mathrm{c}$ & $2,64 b$ & $16,3 b$ & $22,4 \mathrm{a}$ & $1,4 \mathrm{a}$ & $7,1 \mathrm{a}$ & $3,9 \mathrm{c}$ & $8,7 \mathrm{~b}$ & $23,3 \mathrm{c}$ \\
\hline PS-04 & $21,30 \mathrm{c}$ & $12783,6 b$ & $0,91 \mathrm{c}$ & $3,43 \mathrm{a}$ & $17,2 \mathrm{a}$ & $22,6 \mathrm{a}$ & $1,3 b$ & $6,5 \mathrm{a}$ & $4,3 \mathrm{c}$ & $8,8 \mathrm{~b}$ & $21,4 \mathrm{c}$ \\
\hline PS-05 & $25,88 b$ & $16981,3 b$ & $1,19 \mathrm{c}$ & $3,03 \mathrm{a}$ & $17,4 \mathrm{a}$ & $21,4 b$ & $1,2 \mathrm{c}$ & $6,3 a$ & $4,5 b$ & $9,5 b$ & $16,8 \mathrm{~d}$ \\
\hline PS-06 & $28,12 b$ & $20660,5 b$ & $1,48 b$ & $2,72 b$ & $17,0 \mathrm{a}$ & $23,6 a$ & $1,4 \mathrm{a}$ & $5,9 \mathrm{~b}$ & $5,1 \mathrm{a}$ & $10,4 \mathrm{~b}$ & $30,2 b$ \\
\hline PS-07 & $17,90 \mathrm{c}$ & $11774,3 b$ & $0,81 \mathrm{c}$ & $3,10 \mathrm{a}$ & $17,3 \mathrm{a}$ & $24,2 \mathrm{a}$ & $1,4 \mathrm{a}$ & $6,9 a$ & $4,1 b$ & $13,0 \mathrm{a}$ & $42,4 \mathrm{a}$ \\
\hline PS-08 & $19,74 \mathrm{c}$ & $14245,3 b$ & $1,03 \mathrm{c}$ & $2,87 \mathrm{~b}$ & $16,0 \mathrm{~b}$ & $22,8 \mathrm{a}$ & $1,4 \mathrm{a}$ & $6,1 b$ & $4,3 \mathrm{c}$ & $8,8 \mathrm{~b}$ & $28,1 \mathrm{~b}$ \\
\hline PS-09 & $30,70 b$ & $21614,0 \mathrm{~b}$ & $1,53 b$ & $2,89 \mathrm{~b}$ & $16,7 \mathrm{a}$ & $23,3 \mathrm{a}$ & $1,4 \mathrm{a}$ & $6,8 \mathrm{a}$ & $4,3 c$ & $9,0 \mathrm{~b}$ & $29,2 b$ \\
\hline PS-10 & $42,42 \mathrm{a}$ & $27614,4 a$ & $1,96 \mathrm{a}$ & $3,16 \mathrm{a}$ & $16,9 \mathrm{a}$ & $22,7 \mathrm{a}$ & $1,4 \mathrm{a}$ & $6,1 b$ & $4,6 b$ & $9,2 \mathrm{~b}$ & $28,1 \mathrm{~b}$ \\
\hline PS-11 & $48,37 \mathrm{a}$ & $33432,3 a$ & $2,38 \mathrm{a}$ & $2,88 \mathrm{~b}$ & $15,9 b$ & $22,3 \mathrm{a}$ & $1,4 \mathrm{a}$ & $5,6 \mathrm{c}$ & $4,5 b$ & $9,5 b$ & $28,0 \mathrm{~b}$ \\
\hline PS-12 & $30,56 b$ & $22124,6 b$ & $1,57 b$ & $2,77 \mathrm{~b}$ & $17,0 \mathrm{a}$ & $22,5 \mathrm{a}$ & $1,4 \mathrm{a}$ & $6,6 a$ & $4,2 \mathrm{c}$ & $9,7 \mathrm{~b}$ & $20,6 \mathrm{c}$ \\
\hline Média & 26,76 & 18761,93 & 1,33 & 2,88 & 16,7 & 22,5 & 1,4 & 6,3 & 4,4 & 9,5 & 26,1 \\
\hline $\mathrm{Fc}$ & $6,04 * *$ & $6,22 * *$ & $6,2 * *$ & $4,9 * *$ & $2,75^{* *}$ & $3,5 * *$ & $5,6 * *$ & $7,6 * *$ & $2,9 * *$ & $7,7 * *$ & $68,2 * *$ \\
\hline $\mathrm{CV}$ & 28,39 & 26,46 & 26,54 & 8,16 & 4,2 & 4,2 & 3,1 & 5,9 & 7,3 & 8,1 & 5,46 \\
\hline
\end{tabular}

PROD: produtividade, NTF: número total de frutos por hectare, NFP: número de frutos por planta, PMF: peso médio do fruto, DT: diâmetro transversal, DL: diâmetro longitudinal, IF: índice de formato, CI: cavidade interna, EP: espessura da polpa, SS: teor de sólidos solúveis, FP: firmeza da polpa, $\mathrm{F}_{\mathrm{C}}$ : valor do $\mathrm{F}$ calculado. Médias seguidas pela mesma letra pertencem ao mesmo grupo pelo teste de Scott-Knott a 5\% de significância. ${ }^{* *}$ significativo pelo teste $\mathrm{F}$ de Snedecor $(\mathrm{p}<0,01)$. ${ }^{\text {ns }}$ não significativo pelo teste $\mathrm{F}$ de Snedecor

de sólidos solúveis no suco extraído da polpa, é um fator tradicionalmente usado para definir a qualidade do melão, embora em alguns casos essa característica seja considerada como um indicador de qualidade falho (BIANCO; PRATT, 1977). A maioria dos países utiliza os valores do conteúdo de sólidos solúveis como o principal guia de mercado para a aceitação. $O$ valor mínimo recomendado para a Europa para o melão Pele de Sapo, segundo Filgueiras et al. (2000), é de 11\%. Assim sendo, apenas as linhagens dos dois primeiros grupos estariam dentro do valor mínimo aceitável. Não obstante, frutos com valores acima de $10 \%$ têm sido comercializados no porto de Natal (SALES JÚNIOR et al., 2006).

Com relação ao grupo de linhagens de melão Honey Dew, constatou-se para a produtividade a formação de três grupos três grupos de linhagens (TAB. 2). O primeiro, formado pelas linhagens mais produtivas, com médias superiores a $30 \mathrm{t} \mathrm{ha}^{-1}$, foi composto pelas linhagens OF-01, OF-02 e OF-03. O segundo, formado por linhagens com produtividades superiores a $20 \mathrm{t} \mathrm{ha}^{-1}$, foi composto pelas linhagens OF-05, OF-06, OF-07, OF-08, OF-09 e OF-10. A produtividade, segundo os produtores, garante lucro na lavoura meloeira quando é superior a $25 \mathrm{t} \mathrm{ha}^{-1}$. Considerando esse limite mínimo, as linhagens OF-01, OF-02 e OF-03 se destacaram dentre aquelas do tipo Honey Dew avaliadas (TAB. 2).

Formaram-se dois grupos de linhagens para peso médio do fruto. O primeiro foi composto por $75 \%$ das linhagens avaliadas, com pesos variando de 1,35 a $1,62 \mathrm{~kg}$. O segundo grupo foi formado por apenas três linhagens (OF-04, OF-11 e OF-12) com frutos menores, entre 0,93 e 1,20 kg (TAB. 2). Com relação ao peso médio do fruto, para o caso do tipo Honey Dew, valores entre 1,4 e 1,7 kg são preferidos nos contratos estabelecidos entre empresas exportadoras e os importadores europeus. No presente trabalho, quase todas as linhagens estão dentro desse intervalo ou próximo dele. Apenas as linhagens OF04, OF-11 e OF-12 possuem frutos muito reduzidos para o tipo Honey Dew.

Para diâmetro transversal, as linhagens foram discriminadas em três grupos (TAB. 2). O primeiro, formado apenas pela linhagem OF-03, com fruto mais largo. O segundo contemplou 50\% das linhagens, enquanto o terceiro foi composto pelas linhagens OF-04, OF-07, OF-08, OF-11 e OF-12. 
Tabela 2 - Médias de onze características avaliadas em doze linhas de melão Honey Dew. Mossoró-RN, 2004

\begin{tabular}{|c|c|c|c|c|c|c|c|c|c|c|c|}
\hline \multirow{3}{*}{ Linha } & \multicolumn{11}{|c|}{ Médias (características) } \\
\hline & PROD & PMF & DT & $\mathrm{DL}$ & \multirow{2}{*}{ IF } & $\mathrm{CI}$ & EP & $\mathrm{PP}$ & SS & FP & $\mathrm{CC}$ \\
\hline & (t ha-1) & $(\mathrm{kg})$ & $(\mathrm{cm})$ & $(\mathrm{cm})$ & & $(\mathrm{cm})$ & $(\mathrm{cm})$ & $(\%)$ & $(\%)$ & $(\mathrm{N})$ & $(\%)$ \\
\hline OF-01 & $26,11 \mathrm{a}$ & $1,51 \mathrm{a}$ & $11,1 b$ & $11,7 \mathrm{a}$ & $1,1 \mathrm{~b}$ & $5,4 a$ & $2,8 \mathrm{a}$ & $2,3 b$ & $12,1 \mathrm{a}$ & $32,0 \mathrm{a}$ & $58,5^{\mathrm{a}}$ \\
\hline OF-02 & $26,28 \mathrm{a}$ & $1,50 \mathrm{a}$ & $11,2 b$ & $10,7 b$ & $0,9 \mathrm{~d}$ & $4,9 b$ & $2,6 b$ & $3,4 b$ & $12,2 \mathrm{a}$ & $29,5 b$ & $46,5 b$ \\
\hline $\mathrm{OF}-03$ & $27,42 \mathrm{a}$ & $1,61 \mathrm{a}$ & $12,1 \mathrm{a}$ & $12,2 \mathrm{a}$ & $1,0 \mathrm{c}$ & $5,9 a$ & $3,3 \mathrm{a}$ & $2,8 b$ & $11,5 \mathrm{a}$ & $29,7 b$ & $58,0 \mathrm{a}$ \\
\hline OF-04 & $17,54 b$ & $0,93 b$ & $9,6 \mathrm{c}$ & $10,9 b$ & $1,2 \mathrm{a}$ & $3,9 \mathrm{c}$ & $1,9 b$ & $3,2 \mathrm{~b}$ & $9,7 \mathrm{a}$ & $27,1 \mathrm{c}$ & $36,7 \mathrm{c}$ \\
\hline OF-05 & $17,48 b$ & $1,56 \mathrm{a}$ & $10,8 b$ & $11,7 \mathrm{a}$ & $1,1 b$ & $5,1 b$ & $3,2 \mathrm{a}$ & $4,9 \mathrm{a}$ & $11,7 \mathrm{a}$ & $29,9 b$ & $49,1 b$ \\
\hline OF-06 & $17,41 b$ & $1,56 \mathrm{a}$ & $10,8 b$ & $11,7 \mathrm{a}$ & $1,1 b$ & $5,1 b$ & $3,2 \mathrm{a}$ & $4,9 a$ & $11,3 \mathrm{a}$ & $29,4 b$ & $49,0 \mathrm{~b}$ \\
\hline OF-07 & $14,94 b$ & $1,40 \mathrm{a}$ & $10,5 \mathrm{c}$ & $11,5 \mathrm{a}$ & $1,1 b$ & $4,8 \mathrm{~b}$ & $2,9 \mathrm{a}$ & $4,5 \mathrm{a}$ & $11,1 \mathrm{a}$ & $29,1 \mathrm{c}$ & $45,9 b$ \\
\hline OF-08 & $14,17 b$ & $1,35 \mathrm{a}$ & $10,4 \mathrm{c}$ & $11,4 \mathrm{a}$ & $1,1 b$ & $4,7 \mathrm{c}$ & $2,8 \mathrm{a}$ & $4,4 a$ & $10,6 a$ & $28,3 \mathrm{c}$ & $44,9 b$ \\
\hline OF-09 & $16,34 b$ & $1,48 \mathrm{a}$ & $10,7 b$ & $11,6 \mathrm{a}$ & $1,1 b$ & $4,9 b$ & $3,1 \mathrm{a}$ & $4,5 \mathrm{a}$ & $12,4 \mathrm{a}$ & $31,1 \mathrm{a}$ & $47,7 b$ \\
\hline OF-10 & $18,51 b$ & $1,62 \mathrm{a}$ & $10,9 b$ & $11,8 \mathrm{a}$ & $1,1 b$ & $5,2 \mathrm{~b}$ & $3,3 \mathrm{a}$ & $5,1 \mathrm{a}$ & $10,1 \mathrm{a}$ & $27,6 \mathrm{c}$ & $50,4 \mathrm{~b}$ \\
\hline OF-11 & $10,74 b$ & $1,13 b$ & $9,9 \mathrm{c}$ & $11,2 b$ & $1,1 \mathrm{a}$ & $4,3 c$ & $2,4 b$ & $3,8 b$ & $10,6 \mathrm{a}$ & $28,5 \mathrm{c}$ & $40,7 \mathrm{c}$ \\
\hline OF-12 & $11,76 \mathrm{~b}$ & $1,20 \mathrm{~b}$ & $10 \mathrm{c}$ & $11,3 b$ & $1,1 \mathrm{a}$ & $4,4 c$ & $2,5 b$ & $3,9 \mathrm{a}$ & $10,7 \mathrm{a}$ & $28,0 \mathrm{c}$ & $41,9 \mathrm{c}$ \\
\hline Média & 18,23 & 1,4 & 10,7 & 11,5 & 1,1 & 4,9 & 2,8 & 3,9 & 11,2 & 29,2 & 47,5 \\
\hline $\mathrm{Fc}$ & $16,38 * *$ & $5,6^{* *}$ & $8,9^{* *}$ & $4,5^{* *}$ & $11 * *$ & $9,2 * *$ & $4,5^{* *}$ & $6,4^{* *}$ & $1,9^{\text {ns }}$ & $4,5^{* *}$ & $14 * *$ \\
\hline $\mathrm{CV}$ & 9,96 & 11,11 & 3,55 & 3,0 & 2,48 & 6,46 & 12,15 & 15,97 & 9,42 & 4,01 & 6,31 \\
\hline
\end{tabular}

PROD: produtividade, NTF: número total de frutos por hectare, PMF: peso médio do fruto, DT: diâmetro transversal, DL: diâmetro longitudinal, IF: índice de formato, CI: cavidade interna, EP: espessura da polpa, PP: perda de peso, SS: teor de sólidos solúveis, FP: firmeza da polpa, CC: concentração de colheita, $\mathrm{F}_{\mathrm{C}}$ : valor do $\mathrm{F}$ calculado. Médias seguidas pela mesma letra pertencem ao mesmo grupo pelo teste de Scott-Knott a 5\% de significância. ${ }^{* *}$ significativo pelo teste $\mathrm{F}$ de Snedecor $(\mathrm{p}<0,01)$. ${ }^{\mathrm{ns}}$ não significativo pelo teste $\mathrm{F}$ de Snedecor

Para o diâmetro longitudinal, foram formados dois grupos (TAB. 2). O primeiro grupo, com maiores diâmetros, foi composto por $66,67 \%$, enquanto o segundo, por quatro linhagens (OF-02, OF-04, OF-11 e OF-12).

A relação entre os diâmetros transversal e longitudinal permite o cálculo do índice de formato do fruto. No presente estudo, houve maior discriminação para o índice de formato, com quatro grupos formados. Todavia, observando a composição dos grupos, constata-se que os grupos 3 e 4 são formados apenas por uma linhagem, respectivamente OF-03 e OF-02. A maioria das linhagens $(58,33 \%)$ foi alocada no segundo grupo (TAB. 2). Embora tenha havido a formação dos quatro grupos, as estimativas do índice de formato evidenciam que os frutos das linhagens apresentaram frutos com formato arredondados, característicos do melão do tipo Honey Dew.

Concernente à cavidade interna, foram formados três grupos de linhagens (TAB. 2). O primeiro, com maior cavidade interna do fruto, foi composto por apenas duas linhagens (OF-01 e OF-03). O segundo grupo foi formado por $50 \%$ das linhagens, com valores médios variando de 4,8 a $5,2 \mathrm{~cm}$. O terceiro grupo contemplou linhagens de menor cavidade.
As linhagens foram agrupadas em dois grupos para espessura da polpa. No primeiro grupo, formado por maioria das linhagens $(66,67 \%)$, foram alocadas as linhagens com maior espessura da polpa, com uma amplitude de $0,5 \mathrm{~cm}$. O segundo grupo foi formado pelas linhagens com menor espessura de polpa, com as linhagens OF-02, OF-04, OF-11 e OF-12 (TAB. 2).

Os valores das características cavidade interna e espessura da polpa concordam com as estimativas obtidas para esse tipo de melão no Agropolo MossoróAssu (SILVA et al., 2002). As características cavidade interna e espessura da polpa geralmente são inversamente correlacionadas. Em outras palavras, quanto maior a espessura da polpa menor é a cavidade interna. O fruto com cavidade menor reduz a movimentação das sementes e da placenta, contribuindo para a sua conservação.

Para a perda de peso, as linhagens foram divididas em dois grupos (TAB. 2). O primeiro grupo, composto por sete indivíduos, foi formado pelas linhagens com maior perda de peso e com amplitude (1,2\%); e o segundo, formado por cinco linhagens, teve maior amplitude (1,5\%). As linhagens OF-01, OF-2, OF-03, OF-04 e OF-11 sobressaíram-se com as menores perdas de peso, 
característica importante para o tempo de vida pós-colheita de frutos de melão.

As linhagens não diferiram quanto ao teor de sólidos solúveis (TAB. 2). Apenas a estimativa pontual da média da linhagem OF-04 apresentou teor de sólidos solúveis inferior a $10 \%$. Entretanto, no porto de Natal, melão do tipo Honey Dew é comercializado com valores de 9\% (SALES JÚNIOR et al., 2006).

Formaram-se três grupos de linhagens para a firmeza da polpa. O primeiro foi composto pelas linhagens OF01 e OF-09, com firmezas superiores a 30 N. O segundo grupo foi formado pelas linhagens OF-02, OF-03, OF-05 e OF-06. O terceiro grupo pelas demais linhagens (TAB. 2). Os valores verificados estão dentro da faixa estabelecida para o melão Honey Dew (NUNES et al., 2004). Todas as linhagens têm firmeza de polpa acima do valor mínimo estabelecido $(22,0 \mathrm{~N})$ para comercialização com a Europa (FILGUEIRAS et al., 2000).

Formaram-se três grupos de linhagens para a concentração de colheita (TAB.2). O primeiro foi composto pelas linhagens OF-01 e OF-03, com concentrações de colheita próximas a $60 \%$. O segundo grupo foi formado por $66,67 \%$ das linhagens, com valores variando de 44,9 (OF-08) a 50,4\% (OF-10). O terceiro grupo pelas linhagens OF-04, OF-11 e OF-12. Os produtores preferem genótipos com maior concentração de colheita. A principal razão é o menor tempo gasto na colheita e economia de recursos com mão-de-obra tanto na colheita propriamente dita como no processo de certificação de qualidade pós-colheita no "packing house" das fazendas.

Foram constatadas linhagens com ótimo desempenho, com estimativas de médias (TAB. 1 e 2) dentro da faixa de valores médios observados para híbridos de melão Pele de Sapo (NUNES et al., 2004) e famílias de meios-irmãos de melão Honey Dew (SILVA et al., 2002). Esse fato evidencia que é possível obter genótipos homozigotos no meloeiro, sem reduções drásticas devido à depressão por endogamia. É fato conhecido entre os pesquisadores que as cucurbitáceas, de um modo geral, não têm depressão por endogamia acentuada, provavelmente pelo fato dessas espécies serem mantidas em pequenas populações, eliminando-se os alelos deletérios existentes (MALUF, 2001). Todavia, baixa depressão por endogamia não significa ausência de heterose, que é largamente aproveitada na obtenção de híbridos de melão. Ressaltase que atualmente, quase todas as cultivares utilizadas nos Agropólos de Mossoró - Assú - RN e do Vale do Jaguaribe-CE, principais produtores e exportadores do país, são híbridos simples.

Foi constatada a formação de quatro grupos de linhagens Pele de Sapo conforme o critério de Tocher (TAB. 3). Os grupos II, III e IV foram compostos por apenas uma linhagem, respectivamente, PS-01, PS-05 e PS-07, enquanto o grupo I, pelas demais linhagens.

Tabela 3 - Agrupamento de linhagens do tipo Pele de Sapo e Honey Dew conforme a metodologia de Tocher. Mossoró-RN, 2004

\begin{tabular}{|c|c|c|c|c|c|c|}
\hline \multicolumn{7}{|c|}{ Grupos } \\
\hline \multicolumn{4}{|c|}{ 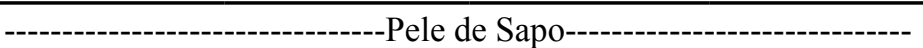 } & \multicolumn{3}{|c|}{ 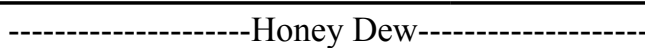 } \\
\hline I & II & III & IV & I & II & III \\
\hline PS-02 & PS-01 & PS-05 & PS-07 & OF-04 & OF-01 & OF-02 \\
\hline PS-03 & & & & OF-05 & OF-03 & \\
\hline PS-04 & & & & OF-06 & & \\
\hline PS-06 & & & & OF-07 & & \\
\hline PS-08 & & & & OF-08 & & \\
\hline PS-09 & & & & OF-09 & & \\
\hline PS-10 & & & & OF-10 & & \\
\hline PS-11 & & & & OF-11 & & \\
\hline PS-12 & & & & OF-12 & & \\
\hline $\mathrm{D}_{\mathrm{I}}=12,3$ & $\mathrm{D}_{\text {II.III }}=20,2$ & $\mathrm{D}_{\text {IIIIV }}=57,8$ & & $\mathrm{D}_{\mathrm{I}}=31,9$ & $\mathrm{D}_{\mathrm{II}}=45,8$ & \\
\hline $\mathrm{D}_{\mathrm{III}}=18,9$ & $\mathrm{D}_{\mathrm{UIV}}=43,5$ & & & $\mathrm{D}_{\mathrm{UII}}=401,8$ & $\mathrm{D}_{\mathrm{HU}}=72,8$ & \\
\hline $\mathrm{D}_{\mathrm{I}, \mathrm{III}}^{\mathrm{I}, \mathrm{II}}=21,1$ & & & & $\mathrm{D}_{\mathrm{I}, \mathrm{III}}^{\mathrm{III}}=198,1$ & & \\
\hline $\mathrm{D}_{\text {IVI }}=29,3$ & & & & & & \\
\hline
\end{tabular}


Verificou-se a formação de dois grupos de linhagens Honey Dew. O grupo II formado pelas linhagens OF-01 e OF-03 e o primeiro pelas demais linhagens (TAB. 3).

Utilizando-se o agrupamento hierárquico UPGMA, verificou-se para o grupo Pele de Sapo, que a classificação das linhagens, considerando como ponto de corte a média das distâncias, resultou na formação de cinco grupos. O primeiro grupo formado pela linhagem PS-07. O segundo, pelas linhagens PS-04 e PS-05; o terceiro, pelas linhagens PS-06, PS-10 PS-11; o quarto pelas linhagens PS-02, PS-03, PS-08, PS-09 e PS-12, o último grupo pela linhagem PS-01. Para o grupo Honey Dew, o resultado dos grupos formados foi o mesmo do critério de Tocher (FIG. 1).
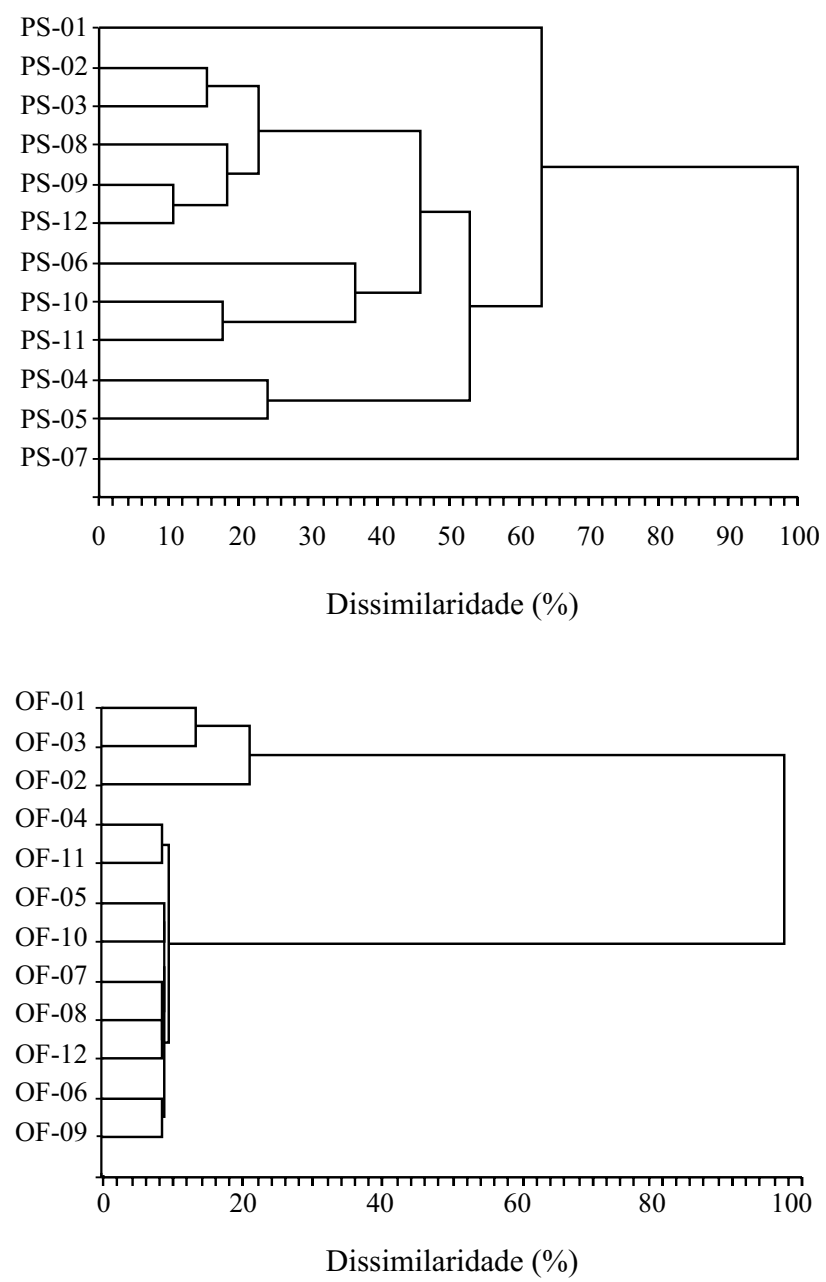

Figura 1 - Dendrogramas baseado em UPGMA, obtido a partir das distâncias generalizadas de Mahalanobis de doze linhagens de melão Pele de Sapo (a) e Honey Dew (b) avaliadas no município de Mossoró-RN. Mossoró-RN, 2004. $\left(\mathrm{CC}_{\mathrm{PS}}=0,76^{* *}\right.$; $\left.\mathrm{CC}_{\mathrm{HD}}=0,90^{* *}\right)$. CC: correlação cofenética
As características que mais contribuíram para a divergência entre as linhagens Pele de Sapo foram firmeza de polpa e sólidos solúveis, explicando 56,63 e 17,20\% da variação total, respectivamente. Para as linhagens Honey Dew as características que mais contribuíram foram número total de frutos $(41,49 \%)$ e produtividade (16,75\%). Paiva (2002), estudando a divergência entre as linhagens e a heterose de seus híbridos, verificou que o teor de sólidos solúveis foi a característica que mais contribuiu para a divergência, com mais de $38 \%$, seguida do formato do fruto. Rizzo e Braz (2002) constataram que o teor de sólidos solúveis foi uma das características de maior contribuição para a divergência genética entre linhagens de melão rendilhado, com 11,60\% (TAB. 4). As referidas características são as mais importantes durante a seleção de frutos voltados para exportação.

A formação de grupos de linhagens via Tocher e UPGMA auxilia no planejamento das combinações híbridas a serem obtidas. O objetivo é indicar cruzamentos que envolvam linhagens alocadas em grupos distintos pelas informações de diversidade genética. Espera-se que os híbridos promissores possam ser gerados por linhagens divergentes. Dentro de cada grupo, recomenda-se a identificação das linhagens de interesse a partir das estimativas das médias das características mais importantes do meloeiro.

No tocante à linhagem PS-07, originada do cruzamento entre os híbridos PS-07 e Tendency, herdou de ambos a excelente qualidade do fruto, ou seja, alto teor de sólidos solúveis (13\%) e elevada firmeza da polpa $(42,43 \mathrm{~N})$. Todavia, a linhagem PS-07 herdou uma baixa produtividade, característica dos híbridos HPS-07 e Tendency, razão da parcial rejeição por parte dos produtores de ambos. Esta linhagem poderia ser cruzada com as demais linhagens, pois foi a mais divergente (TAB. 2 e 3). Assim, poderiam ser gerados onze híbridos simples para futuras avaliações em vários locais do Agropolo Mossoró-Assu.

As linhagens PS-01 e PS-05, também originárias do cruzamento HPS-07 e Tendency, poderiam ser cruzadas com as demais linhagens, assim como a linhagem PS-07. Contudo, vale ressaltar que a linhagem PS-01 possui uma série de características indesejáveis como reduzida produtividade, tamanho do fruto abaixo do desejado para o melão Pele de Sapo e baixa qualidade de fruto, devido aos reduzidos valores de sólidos solúveis e firmeza da polpa (TAB. 1). Um aspecto positivo é a menor cavidade interna da mesma, fato importante para a pós-colheita do fruto. A linhagem PS-05 possui fruto em tamanho comercial, mas frutos de qualidade reduzida.

Com relação às linhagens constituintes do grupo I de Tocher, destacaram-se as linhagens PS-09; PS-10; 
Tabela 4 - Contribuição de cada característica para divergência genética pelo critério de Singh entre linhagens de melão Pele de Sapo e linhagens Honey Dew, avaliadas no Agropólo Mossoró-Assu. Mossoró-RN, 2001

\begin{tabular}{ccc}
\hline \multirow{2}{*}{ Característica } & \multicolumn{2}{c}{ Contribuição para divergência genética (\%) } \\
\cline { 2 - 3 } & Pele de Sapo & Honey Dew \\
\hline${\text { Produtividade }\left(\mathrm{kg} \mathrm{ha}^{-1}\right)}_{\text {Número frutos planta }^{-1}}^{6,19}$ & 16,75 \\
Número total de frutos $^{1}$ & 4,50 & $\mathrm{na}^{1}$ \\
Peso médio do fruto $(\mathrm{g})$ & 7,38 & 41,49 \\
Diâmetro transversal (cm) & 0,05 & 15,11 \\
Diâmetro longitudinal (cm) & 0,90 & 3,71 \\
Índice de formato & 3,18 & 6,36 \\
Cavidade interna (cm) & 1,87 & 1,31 \\
Espessura da polpa $(\mathrm{cm})$ & 1,34 & 3,73 \\
Perda de peso (\%) & 0,78 & 1,13 \\
Sólidos solúveis totais (\%) & na & 6,69 \\
Firmeza da polpa (N) & 17,20 & 0,99 \\
Concentração de colheita (\%) & 56,63 & 0,98 \\
\end{tabular}

${ }^{1}$ na: Não foi avaliada

PS-11 e PS-12, todas com elevadas produtividades ( $\left.\geq 30 \mathrm{tha}^{-1}\right)$ e valores satisfatórios para sólidos solúveis e firmeza da polpa (SALES JUNIOR et al., 2006). Já as demais linhagens deste grupo I devem, prioritariamente, ser incluídas em cruzamentos com as linhagens dos outros grupos (PS-01, PS-05 e PS-07). As linhagens PS-09; PS-10; PS-11 e PS-12 foram obtidas por autofecundação do híbrido Sancho, o principal cultivar de melão Pele de Sapo do Agropolo Mossoró-Assu. Este híbrido é plantado em todas as fazendas exportadoras de melão, destacando-se pela alta produtividade e teor de sólidos solúveis próximo a $12 \%$. Sendo, por isso, denominado de "melão Rei" por muitos produtores.

Concernente às linhagens do tipo Honey Dew recomenda-se os cruzamentos das linhagens OF-01 ou OF-02, produtivas, com maior concentração de colheita e menor perda de peso, com as demais linhagens avaliadas. A linhagem OF-03, com características semelhantes às linhagens OF-01 ou OF-02 também pode ser cruzada com as demais linhagens.

As linhagens OF-01, OF-02 e OF-03, todas originadas de autofecundações do híbrido Honey Dew, divergiram, principalmente, devido à produtividade (TAB. 2). As linhagens do grupo I têm baixas produtividades, mas boa qualidade do fruto (SST $\geq 10 \%$ e FP $\geq 27 \mathrm{~N}$ ).

As linhagens OF-06; OF-07; OF-08 e OF-03e OF09 são originadas do híbrido Saturno, cuja polpa é verde.
Cruzamentos das mesmas com as linhagens OF-01, OF02 e OF-03 resultariam, na maioria, em fruto com polpa salmão, pois a cor salmão é dominante sobre a coloração verde (MONFORTE et al., 2004). Vale ressaltar que praticamente todo o melão Honey Dew exportado no Rio Grande do Norte tem polpa de cor salmão, e apenas uma empresa tem exportado frutos com polpa verde.

\section{Conclusão}

No tipo de melão Pele de Sapo, as linhagens PS01, PS-05 e PS-7 devem ser cruzadas entre si ou com as demais linhagens do grupo I. Para o tipo Honey dew, cruzamentos da linhagem OF-01 ou da linhagem OF-02 com as demais linhagens avaliadas devem ser realizados. A linhagem OF-03, com características semelhantes às linhagens OF-01 ou OF-02 pode ser cruzada com as demais linhagens do grupo I para exploração da heterose.

\section{Referências}

BIANCO, V. V.; PRATT, H. K. Compositional changes in muskmelon during development and in response to ethylene treatment. Journal of the American Society Horticultural Science, v. 102, n. 01, p. 127-133, 1977.

BRAZ, L. T.; RIZZO, A. A. N.; CARDOSO, A. I. I. Divergência Genética entre genótipos de melão rendilhado 
para cultivo em ambiente protegido. Horticultura Brasileira, v. 22, p. 413. 2004. Supelmento.

BHERING, L. L. et al. Alternative methodology for Scott-Knott test. Crop Breeding and Applied Biotechnology, v. 08, n. 01, p. $9-16,2008$

CARMO FILHO, F.; OLIVEIRA, O. F. Mossoró: um município do semi-árido nordestino - características e aspectos florísticos. 1989, 62 p. (Coleção Mossoroense, Série B, n. 672)

CRAMER, C. S.; WEHNER, T. C. Little heterosis for yield and yield components in hybrids of six cucumber inbreds. Euphytica, v. 110, n. 02, p. 99-108, 1999.

CRUZ, C. D.; REGAZZI, A. J.; CARNEIRO, P. C. S. Modelos biométricos aplicados ao melhoramento genético. Viçosa: Editora UFV, 2004. 480 p. v. 1.

CRUZ, C. D. Programa GENES: Diversidade genética. Viçosa: Editora UFV, 2008. 278 p.

DIAS, R. C. S. et al. Cadeia produtiva do melão. In: CASTRO, A. M. G. et al. Cadeias Produtivas e Sistemas Naturais: Prospecção Tecnológicas. Brasília: EMBRAPASPI, 1998. p. 440-493.

FILGUEIRAS, H. A. C. et al. Colheita e manuseio pós-colheita. In: FILGUEIRAS, H. A. C., MENEZES, J. B., ALVES, R. E. Melão: pós-colheita. Brasília: EMBRAPA-SPI/FRUTAS DO BRASIL, 2000. p. 23-41.

FREITAS, J. G. et al. Interação entre genótipo e ambiente em híbridos de melão amarelo no Nordeste do Brasil. Revista Ciência Agronômica, v. 38, n. 02, p. 176-181, 2007.

GATTI, I. et al. Selección de progenitores em espárrago. Horticultura Brasileira, v. 21, n. 02, p. 163-166, 2003.

GURGEL, F. L. et al. Indicação de híbridos de melão para o Rio Grande do Norte. Revista Ceres, v. 52, v. 299, n. 02, p.115-123, 2005.

GUSMINI, G.; WEHNER, T.C. Fifty-five Years of Yield Improvement for Cucumber, Melon, and Watermelon in the United States. HortTechnology, v. 18, n. 01, p. 9-12, 2008.

LIMA, L. L., NUNES, G. H. S.; BEZERRA NETO, F. Coeficientes de variação de algumas características do meloeiro: uma proposta de classificação. Horticultura Brasileira, v. 22, n. 01, p. 14-17, 2004.

MALUF, W. R.; FERREIRA, P. E.; MIRANDA, J. E. C. Genetic divergence in tomatoes and its relationship with heterosis for yield in $\mathrm{F}_{1}$ hybrids. Revista Brasileira de Genética, v. 03, n. 02, p. $453-460,1983$.
MALUF, W. R. Heterose e emprego de híbridos F1 em hortaliças. In: NASS, Luciano Lourenço et al.(Org.). Recursos Genéticos e Melhoramento-Plantas. Rondonópolis-MT: Fundação MT, 2001, p. 327-355.

MARTINELLO, G. E. et al. Divergência genética em acessos de quiabeiro com base em marcadores morfológicos. Horticultura Brasileira, v. 20, n. 01, p. 52-57, 2002.

MIRANDA, J. E. C.; CRUZ, C. D.; COSTA, C. P. Predição do comportamento de híbridos de pimentão (Capsicum annum L.) pela divergência genética dos progenitores. Revista Brasileira de Genética, v. 11, n. 03, p. 929-937, 1988.

MONFORTE. A. J.; OLIVER.M.; GONZALO. M. J. Identification of quantitative trait loci involved in fruit quality traits in melon (Cucumis melo L.). Theoretical Applied Genetic, v. 108, n. 02, p. 750-758, 2004.

MONTGOMERY, D. C.; PECK, E. A. Introduction to linear regression analysis. New York: John Wiley, 1981. 504 p.

NUNES, G. H. de S.; SANTOS JÚNIOR, J. J. S.; VALE, F. A.; BEZERRA NETO, F.; ALMEIDA, A. H. B.; MEDEIROS, D. C. Aspectos produtivos e de qualidade de híbridos de melão cultivados no Agropolo Mossoró-Assu. Horticultura Brasileira, Brasília, v.22, n.4, p.744-747, dez, 2004.

NUNES, G. H. S. et al. Desempenho de híbridos do grupo inodorus em Mossoró. Horticultura Brasileira, v. 23, n. 01, p. 90-94, 2005.

PAIVA, W. O. Divergência genética entre linhagens de melão e a heterose de seus híbridos. Horticultura Brasileira, v. 20, n. 01 , p. 34-37, 2002.

RIZZO, A.; BRAZ, L. T. Divergência genética entre cinco genótipos de melão rendilhado. Horticultura Brasileira, v. 20, n. 02, p. 171-173, 2002.

SALES JÚNIOR, R. et al. Aspectos qualitativos do melão exportado pelo porto de Natal-RN. Ciência Rural, v. 36, p. 286-289, 2006.

SILVA, R. A. et al. Estimação de parâmetros e correlações em famílias de meio-irmãos de melões Orange Flesh HTC. Caatinga, v. 15, n. 01/02, p. 43-48, 2002.

TORRES FILHO, J. Caracterização morfo-agronômica, seleção de descritores e associação entre a divergência genética e a heterose no meloeiro. 2008. $150 \mathrm{f}$. (Tese de Doutorado) - Universidade Federal Rural do Semi-Árido, Mossoró. 